\title{
Insensitivity to verb conjugation patterns in French SLI
}

\section{Insensitivity to verb conjugation patterns in French children with SLI}

\author{
Phaedra Royle ${ }^{1,2,3}$, Ariane St-Denis ${ }^{1}$, Patrizia Mazzocca ${ }^{4}$, Alexandra Marquis $^{5}$ \\ ${ }^{1}$ École d'orthophonie et d'audiologie, Université de Montréal \\ ${ }^{2}$ Centre for Research on Brain, Language and Music \\ ${ }^{3}$ International Laboratory for Brain, Music, and Sound Research \\ ${ }^{4}$ Institut Raymond Dewar, Montréal \\ ${ }^{5}$ Department of Linguistics, United Arab Emirates University
}

Corresponding author: Phaedra Royle, phaedra.royle@umontreal.ca

AUTHOR PRE-PRINT ACCEPTED MANUSCRIPT

PUBLISHED ARTICLE AVAILABLE AT : http://www.tandfonline.com/loi/iclp20 


\title{
Insensitivity to verb conjugation patterns in French SLI
}

\begin{abstract}
Specific language impairment (SLI) is characterized by persistent difficulties that affect language abilities in otherwise normally developing children (Leonard, 2014). It remains challenging to identify young children affected by SLI in French. We tested oral production of the passé composé tense in 19 children in kindergarten and first grade with SLI aged from 5;6 to 7;4 years. All children were schooled in a French environment, but with different linguistic backgrounds. We used an Android application, Jeu de verbes (Marquis et al., 2012), with six verbs in each of four past participle categories (ending in -é, -i, -u, and Other irregulars). We compared their results and error types to those of control children (from Marquis, 2012-2014) matched for gender, age, languages spoken at home, and parental education. Results show that children with SLI do not master the passé composé in the same way as typical French children do, at later ages than previously shown in the literature. This task shows potential for oral language screening in French-speaking children in kindergarten and first grade, independently of language background.
\end{abstract}

Keywords: Specific language impairment, French, Conjugation groups, Verbs, Morphology 


\section{Insensitivity to verb conjugation patterns in French SLI}

\section{Introduction}

Specific language impairment (SLI) is characterized by persistent difficulties that affect expressive and receptive language abilities (Leonard, 2014), which are reduced compared to other general cognitive abilities. Still today, clinical indicators that enable their identification remain challenging to define. Rice and Wexler (1996) demonstrated that English children with SLI have difficulty producing tense markers (see a review of English studies by Bishop, 2014). Several other studies suggest that children who suffer from SLI have difficulties with verb tense or agreement inflection in Arabic (Abdalla \& Crago, 2008), Danish (Vang Christensen \& Hannson, 2012), Dutch (Spoelman \& Bol, 2012), English (Marshall \& van der Lely, 2007; Paradis \& Crago, 2001; Rice, Wexler \& Cleave, 1995; Ullman \& Gopnik, 1994), Finnish (Kunnari, Savinainen-Makkonen, Leonard, Makinen, Tolonen, Luotonen \& Leinonen, 2011), French (Franck, Cronel-Ohayon, Chillier, Frauenfelder, Hamann, Rizzi, \& Zesiger, 2004; Jakubowicz, 2003; Paradis \& Crago, 2001; Rose \& Royle, 1999; Royle \& Elin Thordardottir, 2008), German (Clahsen, 1989), Greek (Stavrakaki, Chrysomalis \& Petraki, 2011), Hebrew (Dromi, Leonard, \& Shteiman 1993), Hungarian (Leonard, Lukács \& Kas, 2012; Lukács, Leonard, Kas \& Pléh, 2009), Italian (Leonard, Bortolini, Caselli, McGregor, \& Sabbadini, 1992; Pizzioli \& Schelstraete, 2008), Japanese (Gopnik, Dalalakis, Fukuda, Fukuda \& Kehayia, 1996), Norwegian (Simonsen \& Bjerkan, 1998), and Swedish (Hansson, 1997).

Verb production difficulties vary across languages, with some groups of children making more errors on tense and others on subject-verb agreement. Furthermore, some children find it easier to correctly produce inflected verbs in spontaneous speech compared to elicitation tasks. For example, even very young French-speaking children with language impairment tend to make very 


\section{Insensitivity to verb conjugation patterns in French SLI}

few mistakes in spontaneous speech (e.g., Elin Thordardottir \& Namazi, 2007, for pre-school children, but see Paradis \& Crago, 2001 for school-aged children who do show difficulties) but have more difficulty producing appropriate forms in elicitation tasks (Jukubowicz \& Nash, 2001; Jakubowicz, 2003; Rose \& Royle, 1999; Royle \& Elin Thordardottir, 2008). Similar distinctions can be made across languages, with some studies showing major problems in spontaneous verb production (e.g., Arabic: Abdalla \& Crago 2008; Dutch: Spoelman \& Bol, 2012; English: Rice, Wexler \& Cleave, 1995; French: Paradis \& Crago, 2001; Spanish: Bedore \& Leonard, 2005; Swedish: Hannson, Nettelbladt \& Leonard, 2000) and others showing similar results compared to younger language-matched but not age-matched peers (e.g., Hebrew: Dromi et al., 1993; Dromi, Leonard, Adam \& Zadunaisky-Ehrlich, 1999; Italian: Bortolini, Leonard \& Caselli, 1998; Spanish: Bedore \& Leonard, 2001), with still others observing few deficits compared to both language- and age-matched peers (e.g., French: Elin Thordardottir \& Namazi, 2007; Greek: Stavrakaki, 2005; Icelandic: Elin Thordardottir, 2008; Spanish: Bedore \& Leonard, 2005).

However, when tested on more constraining tasks such as sentence completion, sentence repetition with inflection masking, and comprehension, children with SLI fare worse overall than both language- and age-matched controls (e.g., Danish: Lum \& Bleses, 2012; Vang Christensen \& Hansson, 2012; Finnish: Kunnari et al., 2011; Hebrew: Leonard, Dromi, Adam, \& ZadunaiskyEhrlich, 2000; Hungarian: Lukács et al., 2009; Leonard et al., 2012; Italian: Bortolini, Caselli, Deevy \& Leonard, 2002; Norwegian: Simonsen \& Bjerkan, 1998; see below for French).

French children with SLI appear to be unable to make generalizations that allow them to develop schemas for rule generation (Leroy, Parisse, \& Maillart, 2014; Royle \& Elin Thordardottir, 2008), and they show little evidence of overregularization, which is observed in typically developing children (Grégoire, 1937; Hiriarteborde, 1973). Our study focuses on verb inflection 


\section{Insensitivity to verb conjugation patterns in French SLI}

production in French, a language that has three conjugation groups and four inflection patterns for past participle forms. We examine pre-school children's ability to inflect these different forms, and hence their sensitivity to morphological and phonological regularities in French. We begin with a description of how these forms are acquired, followed by explanations for difficulties observed in children with SLI across languages. We then present our study.

\section{Verb inflection in typical French children and children with SLI}

Royle's (2007) study of French verb production showed that correct production of the passé composé (the perfect past tense) is linked to conjugation groups: French children are better at producing regular versus irregular verbs. Moreover, they overgeneralize regular (-e and -i) patterns to irregular forms (e.g., il a ouvri [uvвi] or ouvré [uvse] 'he opened' for il a ouvert [uver]]). These overgeneralizations reflect the acquisition of inflectional rules by French children (Royle, Beritognolo \& Bergeron, 2012).

\section{INSERT TABLE 1 ABOUT HERE}

The French language has three conjugation groups (illustrated in Table 1). The first includes regular and productive verbs that end with -er in the infinitive (e.g., manger [mãze] 'to eat') ${ }^{1}$. The first conjugation is considered to be the default form, as it is used productively to create new verbs (Royle et al., 2012). Young French children produce overgeneralizations into this pattern at ages as young as 3;0 (e.g., il a boivé [bwav-e] instead of il a bu [by] 'he drank', Royle, 2007). The second category comprises verbs with an infinitive ending in -ir (e.g., finir [finir] 'to

\footnotetext{
${ }^{1}$ Only two irregular verbs belong to this group: aller 'to go' and s'en aller 'to leave'. Aller is also used as an auxiliary in the future periphrastic form, e.g., il va ouvrir 'he will open'.
} 


\section{Insensitivity to verb conjugation patterns in French SLI}

finish/end'). It includes regular verbs with present participles ending in -issant (e.g., finissant, 'finishing') and past participles ending in -i (e.g., fini 'finished'), as well as irregular verbs with other forms for the present and past participles (e.g., mourir 'to die', mourant 'dying', mort 'dead'). We refer to the first type as subregular, because they are not part of the default first conjugation group. However they maintain a regular stem and carry regular inflection, in addition to being used in some cases for de-adjectival verb formation and neology (Royle et al., 2012). The third conjugation consists of irregular verbs with an infinitive ending in -(d)re or -oir (and is actually the conflation of the third and fourth conjugations, which are historically distinct). Most of these verbs have stems that undergo changes by vowel or consonant modification, similar to drink - drank in English (e.g., bois-buvez [bwa-byve] '(you.sg) drink-(you.pl) drink') while bearing regular suffixes (e.g., buv-ez 'drink.2pp'). Similar to English children, French children start productively using the past tense around age three years (Bassano, Maillochon, Klampfer \& Dressler, 2001; Elin Thordardottir \& Namazi, 2007). However, unlike in English, the most common past tense form in French is a compound structure involving an auxiliary and the past participle of the main verb. French speakers need to learn not only the past tense rule but also the conjugation group for each verb. Certain verbs in the third group have a past participle ending in -i (similar to the regular second conjugation) while having an unstable stem vowel (e.g., prendrepris [рьа̃dь-рьі] 'to take'). Another subgroup of past participles in irregular verbs end in -u [y] and are considered to be nonproductive (bois-bu [bwa-by] 'drink'. However, this particular verb category contains some of the most frequent verbs in French (Royle et al., 2012). Finally, French includes a small class of highly irregular verbs in the second and third conjugations that have no perceptible pattern for the past participle (see examples in Table 1). 


\section{Insensitivity to verb conjugation patterns in French SLI}

Studies of children without language impairment show differing performance, depending on verb classes. For example, Marquis and Royle (2015) found that children aged 6 to 7 years can successfully inflect verbs ending in $-e ́,-i$, and $-u$, but not $O($ ther) verbs (é $=i=u>O$ ) having completely irregular patterns (e.g., mort 'dead'). Italian-speaking (Junyent, Levorato \& Denes, 2010) and pre-school French-speaking children with SLI (Pizzioli \& Schelstraete, 2008; Royle \& Elin Thordardottir, 2008) have difficulty producing the past tense in elicitation tasks, suggesting that this structure could be useful for identifying language-learning difficulties in Frenchspeaking kindergarten and grade-school children with SLI. Specifically, in French-speaking children with SLI, no differences were found between regular and irregular verb production at age 3 to 4 years (Royle \& Elin Thordardottir, 2008). In addition, neurotypical children who make mistakes in a past tense production task still tend to use the past tense: they may, for example substitute the target verb with a more frequent one or produce overgeneralizations into -é and -i patterns, indicating that they are sensitive to the morphosyntactic constraints of the task (Royle, 2007). Instead of producing overgeneralizations, pre-school-aged children with SLI tend to use the past participle alone or the present tense (Royle \& Elin Thordardottir, 2008).

\section{Explaining verb production difficulties in SLI}

A number of hypotheses for the difficulties with verb inflection in SLI have been suggested. For example, early approaches posited insensitivity to or difficulties with linguistic features such as TENSE or AGR(eement), which are functional projections in syntax (Clahsen, 1989; Clahsen \& Hansen, 1993; Gopnik, 1994; Paradis \& Crago, 2002; Rice, Wexler \& Cleave, 1995; Rice, Wexler \& Hershberger, 1998). Other hypotheses pointed to the morphophonological characteristics of inflection morphemes as the source of difficulties, showing that, for example, 


\section{Insensitivity to verb conjugation patterns in French SLI}

the articulatory properties of English past tense marking (often resulting in complex consonant clusters, such as mixed [mikst] or rained [rajnd]) might make either their perception or production processes difficult (e.g., Leonard et al., 1992; Marshall \& van der Lely, 2007). However, unlike in English, morphological marking in French is syllabic and salient (mostly involving word final vowels) $)^{2}$, and should not impose particular perceptual or articulation difficulties for children. Another approach within the word and rule models of language processing (Clahsen, 1996; Pinker \& Prince, 1992; Ullman, Corkin, Coppola, Hickock, Growden, Koroshetz, \& Pinker, 1997) explains difficulties in children with SLI based on the distinction between regularly inflected verbs (with -ed in English) and irregularly inflected verbs (e.g., went). The argument is that because children with SLI have difficulties applying morphological rules for inflection, they do not have the productive ability to inflect regular verbs, and they must therefore lexicalize all verb forms as chunks, whether they are irregular or not. Thus, they do not show the typical pattern of better production of regular versus irregular targets found in English children (Ullman \& Gopnik, 1994; van der Lely \& Ullman, 2001). This distinction has also been explored in French children by Royle and Elin Thordardottir (2008), who show that Frenchspeaking children with SLI below age 4;06 show equally low responses as control children on regular and irregular past tense forms matched for age of acquisition, even though they may spontaneously produce some appropriate forms in nondirected tasks. Some authors have argued that verb regularity cannot account for the results observed, for example, in a spontaneous speech sample of 14 Swedish-speaking children with SLI aged 4;3 to 5;7. Hansson, Nettelbladt, and Leonard (2000) show that children with SLI have lower mastery of regular verbs but perform

\footnotetext{
${ }^{2}$ Stress is noncontrastive in French in that it serves only to indicate syntactically conditioned phrase boundaries. Stress is realized on the final full (non-schwa) vowel of the phrase. When words are produced in isolation, the stress falls on the final full vowel of the word (Yvan Rose, personal communication).
} 


\section{Insensitivity to verb conjugation patterns in French SLI}

similarly to controls on irregular verbs. In her recent review, Bishop (2014) argues that a syntactic approach to verb inflection difficulties might provide a better explanation of patterns observed in children with SLI. This is not incompatible with Jakubowicz (2003), who proposes that errors found in SLI result from syntactic processing difficulties with complex structures involving movement or functional projections (such as French compound tenses). However, we agree with Bishop's argument that this does not preclude the possibility that these children have other difficulties in morphophonological or morphosyntactic processes.

\section{Our study}

\section{Goals}

This goal of this study was to develop a verb tense production task for early (kindergarten and first grade) SLI screening in French children. A secondary goal was to evaluate the usefulness of a long (24-item) versus short (10-item) version of the task for detecting verb production difficulties. The shorter version is already integrated in a screening tool (PHOPHLO, Prédiction des habiletés orthographiques par des habilités du langage oral [Prediction of orthographic abilities through oral language abilities]) developed to identify children potentially at risk for

writing difficulties, and is one of four tasks designed to evaluate oral language abilities, including speech production and perception, phonological awareness, and morphosyntactic abilities (Rvachew, Royle, Gonnerman, Stanké, Marquis \& Herbay, 2017, resubmitted).

\section{Hypotheses}

Our hypotheses are that children with SLI will perform less well on the task compared to typically developing children, and that due to their difficulty in extracting morphosyntactic rules 


\section{Insensitivity to verb conjugation patterns in French SLI}

(Royle \& Elin Thordardottir, 2008), they will not show better results for regular, sub-regular, or $\mathrm{u}$ verbs over other irregular $(\mathrm{O})$ verbs, contrary to control children, who should show sensitivity to verb schemas. Children with SLI will make significantly fewer overregularizations than control children and will use more infinitive, present, and isolated past participle forms in contexts that require the passé composé.

\section{Methodology}

\section{Participants}

We evaluated 26 children with SLI aged 5;6 to 7;4 years, of which 8 were girls ${ }^{3}$. All children were recruited at a specialised school for children with severe language impairment or at the Speech-language pathology and audiology clinic of the Université de Montréal, both in the Montreal area, and were matched with an equal number of typically developing children who were participants in a study aimed at collecting norming data (Jeu de verbes, Marquis, 20122014). All children were schooled in French. Within the clinical group, four were excluded from the study because their age and educational level did not meet our criteria: two of them were too old (3rd- and 5th-graders) and had already received explicit teaching of verb inflection, and two others were too young (pre-kindergarten). We also excluded one child whose characteristics did not match our definition of $\mathrm{SLI}^{4}$. Two more were excluded due to severe prematurity, which excludes a "pure" SLI diagnosis. Our analyses were performed on the remaining 19 children (of which 6 were girls). Their individual characteristics are presented in Appendix A. We matched

\footnotetext{
${ }^{3}$ Two pairs of children with SLI were twins, see Appendix A.

${ }^{4}$ His language scores for the Échelle de Vocabulaire en Images Peabody (EVIP) (Dunn, Thériault-Whalen, \& Dunn, 1993) and the French version of the Expressive One Word Picture Vocabulary Test (Groupe cooperatif en Orthophonie - Région Laval, 1995) results were average and his language delay was possibly due to significant prematurity.
} 


\section{Insensitivity to verb conjugation patterns in French SLI}

them to 19 children tested by Marquis (2012-2014) while controlling for sex, age, education

level, parental education level, and percentage of French exposure at home in cases where children spoke more than one language. Regarding education level, we ensured that all children were at the same schooling stage, when explicit teaching of inflection is not yet taught (kindergarten and 1st grade, MELS, 2013). It has also been demonstrated that parental education level can be correlated to children's performance on this task (St-Denis, Marquis, \& Royle, 2015). Furthermore, Marquis and Royle (2015) demonstrated that children's linguistic status (either monolingual or multilingual) can impact morphosyntactic abilities (with slighter better responses for multilingual versus monolingual children in first grade). T-tests showed no significant between-group differences on these factors. Table 2 presents the descriptive data for the two groups.

\section{INSERT TABLE 2 ABOUT HERE}

\section{Procedure}

Five different experimenters (the second and fourth author and 3 speech-language pathologists, SLPs) carried out the experiment using the same protocol. The three SLPs were trained by the first and second author to test children they were treating in school, enabling maximum participation by children who may have other behavioural problems. The sessions were recorded, and transcripts were made by the second author and double-checked by a research assistant.

Children were met at the École d'orthophonie et d'audiologie or at their school, in a quiet room of the SLP office. Parents received a letter and consent form from the therapist or researcher 


\section{Insensitivity to verb conjugation patterns in French SLI}

before we met the child. No child was tested without the written consent of a parent, and all children were free to withdraw at any time. A phone interview and parental questionnaires were completed before meeting the child, or were administered at the same time as the child's evaluation. The first questionnaire concerned the child's developmental history. The second questionnaire collected data about the family's literacy habits. The third questionnaire dealt with the family's language habits and allowed us to determine the children's level of exposure to different languages spoken in the home and family environment. Each child participated in three tasks. The two others (a phonological production test, Rvachew, Marquis, Paul, Brosseau-Lapré, Gonnerman \& Royle, 2013, and a morphosyntactic error detection test, unpublished) are not discussed here. The second task was a verb task, Jeu de verbes. Each meeting lasted about 30 minutes, of which slightly more than 10 were allocated to the Jeu de verbes. The research protocol was approved by two ethics committees: the Comité éthique de la recherché en santé (CERES) de l'Université de Montréal and the Comité d'éthique du Centre de recherche de l’hôpital Ste-Justine.

\section{Material: Verb production task}

We administered the Jeu de verbes task, developed by Marquis et al. (2012), on an Android tablet. The experimenter scrolled through a series of images and told a short story for each one. She then asked the child a question in order to have him or her complete the story and thereby produce the compound past tense. The target verb was always presented to the child in the infinitive and present forms, so that he or she could identify the category to which it belonged and then apply the appropriate inflection. An example of the script read by the experimenter and the expected response is presented in 1 below: 


\section{Insensitivity to verb conjugation patterns in French SLI}

1. Image: A girl hiding dolls under a box

Marie va cacher [kafe] ses poupées. Marie cache [kaf] toujours ses poupées. Qu'est-ce qu'elle a fait hier, Marie? Response: Elle a caché [kafe] ses poupées.

'Mary will hide (Inf.) her dolls. Mary always hides (Pres.3ps) her dolls. What did Mary do yesterday? Response: She AUX hide.pp her dolls.'

Stimuli were controlled in terms of frequency, age of acquisition and conjugation pattern. We used the same items as Marquis et al. (2012): 6 verbs from each conjugation group, with past

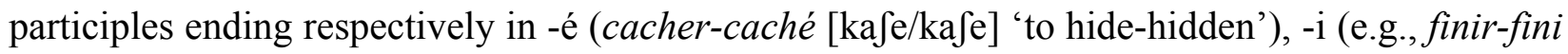
[finıь/fini] 'to finish-finished'), -u (е.g., mordre-mordu [mовd(в)/mэвd ${ }^{\mathrm{z}} \mathrm{y}$ ] 'to bite-bit'), or Other (e.g., ouvrir-ouvert [иүвіь/uvєь] 'to open-opened'). Four additional items (one of each type) were used as practice items, with corrective feedback in case of error. For the 24 target verbs, the child received verbal encouragement after providing each response, accurate or not. Verb groups were matched on frequency measures (from LEXIQUE, New, Pallier, Ferrand, \& Matos, 2001; and MANULEX, Lété, Sprenger-Charolles, \& Colé, 2004, databases for 6-7 year-olds, see Appendices B and C). Form and lemma frequencies did not differ statistically (all p's $>.1$ ). Verb groups were matched for number of phonemes, number of syllables, number of orthographic neighbours, and number of phonological neighbours (all p's > .1). Images illustrating elicited verbs were created by a professional artist (see an example in Appendix D). Stimulus presentation order was the same for all children and was pseudo-randomized so that a maximum of two verbs of a given pattern were presented sequentially to avoid production strategies based 


\section{Insensitivity to verb conjugation patterns in French SLI}

on analogy with preceding items.

\section{Scoring}

We identified children's target productions (one point for each passé composé form, i.e., the auxiliary + past participle) and error types. In both cases, we considered only the child's first response. When the response was prefixed with re- (e.g., elle a ré-écrit 'she re-wrote'), we accepted it as a target response. Because our research question is not related to pronouns, we did not consider either pronoun omission or commission in error compilation (e.g., A cassé les noix for Il a cassé les noix 'he broke the nuts' was accepted). We classified errors into six categories: infinitive, past participle with no auxiliary, present tense, other verb, other response, and overregularization (in -é, -i or -u). As soon as another verb was used, the response was recorded in the "other verb" category, even if the response was related to a phonological error (e.g., attendu [atãdy] 'waited' for entendu [ãtãdy] 'heard'). However, we accepted phonological errors that were similar to the target verb but did not exist as verbs in French (e.g., intendu [ẽtãdy] for entendu). Unintelligible productions were categorized as "other response". Additionally, given the large number of responses in the "other verb" and "other response" categories, we identified response subcategories within each of these. We grouped "other verb" responses into six categories: passé composé, infinitive, past participle, auxiliary + verb (including AUX + infinitive, AUX + present and aller + verb, the compound future form), and other response (including imperfect, pluperfect, overregularization ending in -é and -i, and other incongruous responses). Six "other response" categories were identified: auxiliary + verb (including AUX + infinitive and AUX + present), imperfect, no verb, phonological error, unintelligible, and other incongruous response. 


\section{Insensitivity to verb conjugation patterns in French SLI}

\section{Results}

\section{Global results}

Repeated measures ANOVAs were conducted on the total target response scores on the task (out of 24). Participant group (2 levels, SLI vs. Control) was the between factor, and verb category ${ }^{5}$ was the within factor (4 levels, -é, -i, -u, Other). Mauchly's test was used to test the data for sphericity.

When analysing production of the passé composé form (auxiliary + past participle), we found main effects for both participant group $\left(F(1,36)=21.0, p<.001, \eta^{2}=0.37\right)$ and verb category $\left(F(3,108)=19.3, p<.001, \eta^{2}=0.35\right)$. An interaction between the two factors was also found $\left(F(3,108)=9.24, p<.001, \eta^{2}=0.20\right)$, suggesting that scores do not vary similarly for both participant groups. Table 3 presents these results.

\section{INSERT TABLE 3 ABOUT HERE}

Post-hoc $t$-tests reveal that only the scores for idiosyncratic verbs differ from all other types (-é $=$ $-\mathrm{i}=-\mathrm{u}>\mathrm{O})$ : O vs. -é, $t(36)=1.53, p<.001 ; \mathrm{O}$ vs. $-\mathrm{i}, t(36)=1.13, p<.001 ; \mathrm{O}$ vs. $-\mathrm{u}, t(36)=1.13$, $p<.001$. Further comparisons were made between the two participant groups on scores for the different verb categories. Levine's test of equality of variance showed inequality of variance for all comparisons. Hence, the Greenhouse-Geisser correction was used for the comparison between the two participant groups. $T$-tests show a significant difference in favour of the Control group

\footnotetext{
${ }^{5}$ Note that we established four verb inflection patterns across three verb conjugation groups. We therefore use the term "verb category" or "type" rather than "conjugation group" in our analyses.
} 


\section{Insensitivity to verb conjugation patterns in French SLI}

for all verb types: -é, $t(30.5)=4.73, p<.001$; -I, $t(22.21)=4.87, p<.001 ;-\mathrm{u}, t(26.3)=3.25, p=$ $.003 ; \mathrm{O}, t(24.9)=3.85, p=.001$. Despite the significant participant group differences, we noted considerable heterogeneity within each group, with high variation in scores (SLI: $\operatorname{Min}=0, \operatorname{Med}=$ 1, $\operatorname{Max}=14$; Control: $\operatorname{Min}=1, \operatorname{Med}=18, \operatorname{Max}=21$ ). Finally, post-hoc t-tests were conducted within each group to compare results within the different verb categories. The Control group showed the same pattern as for the main effect above, with a significant difference between scores on the fourth type and all others $(-\mathrm{e}=-\mathrm{i}=-\mathrm{u}>\mathrm{O})$ : $\mathrm{O}$ vs. -é $t(18)=2.47, p<.001$; O vs. -i $t(18)=2.05, p<.001 ; \mathrm{O}$ vs. $-\mathrm{u} t(18)=1.53, p=.005$. In the SLI group, no significant differences were found between verb types.

\section{Analyses of past participle forms}

Because we were interested in sensitivity to morphological patterns, we ran an analysis of the ability to produce the past participle without taking into account the ability to produce a whole complex verb form. We again observed main effects of participant group $(F(1,36)=25.9, p<$ $\left..001, \eta^{2}=0.42\right)$ and verb category $\left(F(3,108)=26.8, p<.001, \eta^{2}=0.43\right)$ as well as an interaction between these two factors $\left(F(3,108)=5.96, p=.002, \eta^{2}=0.14\right)$. Table 4 presents these results.

\section{INSERT TABLE 4 ABOUT HERE}

Post-hoc $t$-tests reveal significant differences between all verb categories except for the second and third categories, which show the following pattern: $-\mathrm{e}>-\mathrm{i}=-\mathrm{u}>$ O. Follow-up comparisons were conducted to determine the verb category on which the two participant groups differed. Equality of variance was met for the Other verbs only. Greenhouse-Geisser corrections were 


\section{Insensitivity to verb conjugation patterns in French SLI}

applied to the three other comparisons. Significant differences in favour of the Control group were found for each verb category: -é, $t(21.7)=6.69, p<.001 ;-\mathrm{i}, t(31.6)=3.47, p=.002$; -u, $t(28.1)=3.34, p=.002 ; \mathrm{O}, t(36)=2.89, p=.006$. Finally, post-hoc $t$-tests within each participant group reveal a similar pattern for the Control group (-é $>-\mathrm{i}=-\mathrm{u}>\mathrm{O}$ ) and a different pattern for the SLI group, with significant differences between the first and fourth category only (-é $>$ O), $t(18)=1.26, p=.049$.

The probability of passing the Jeu de verbes, given group membership (SLI vs. Control), yields a fair sensitivity of $84 \%$ (i.e., proportion of true positives identified) and a lower specificity of $68 \%$ (i.e., proportion of true negatives identified) for Jeu de verbes as a screen for oral language difficulties in this sample (Plante \& Vance, 1994). The data for these calculations are provided in Table 5, along with the likelihood ratio, indicating that a kindergarten or first-grade child with difficulties on this task was 0.52 times more likely to present with a language impairment than a child who did not have difficulties on this task. A further analysis of the results on verb subgroups shows that only the first conjugation type (-é verbs) — or a combination of the first two types (-é and -i) — yielded a fair sensitivity of $84 \%$ and a slightly better specificity of $74 \%$ (Table 6), and with a slightly higher likelihood ratio (0.58).

\section{INSERT TABLE 5 ABOUT HERE}

INSERT TABLE 6 ABOUT HERE

In order to better characterize individual behaviour on the task, we plotted boxplots each group. Results are presented in Figure 1 (overall responses) and Figure 2 (responses by conjugation pattern). The figures also include cut-offs (Mean - $1 \mathrm{SD}$ ) based on a) the full sample of children 


\section{Insensitivity to verb conjugation patterns in French SLI}

in the larger study ( $N=169$, Marquis \& Royle, in preparation) and b) our matched Control group $(n=19)$. As can be seen in Figure 2, the two groups are more readily distinguished on -é and -i items and not so well on Other items, independently of the cut-off used.

INSERT FIGURE 1 ABOUT HERE

INSERT FIGURE 2 ABOUT HERE

\section{Error analysis}

To determine whether nontarget response types differed between the groups and which types were specific to children with SLI, we performed two-level chi-square analyses, with participant group as the between factor (2 levels, SLI vs. Control) and nontarget response types as within factors (6 levels, infinitive, isolated past participle, present tense, overregularization, other verb, other response). A significant difference was found between participant groups and response types, $X^{2}(5, N=632)=98.6, p<.001$. Figure 3 presents nontarget response types for each group. To determine specific differences between the two groups, Mann-Whitney analyses were conducted on the different error types with participant group as the between factor. Due to multiple comparisons, we adjusted our alpha to .008. We found a significant difference for present tense responses, $U=41.0, z=4.29, p<.001$, and other verb responses, $U=45.0, z=$ $3.97, p<.001$, both produced more often by the SLI group (Present: Med $=2$, range 0 to 9; Other verb: $M e d=10$, range 2 to 22) than by controls (Present: $M e d=0$, range 0 to 5; Other verb: Med $=2$, range 0 to 17 ).

INSERT FIGURE 3 ABOUT HERE 


\section{Insensitivity to verb conjugation patterns in French SLI}

As mentioned in the Scoring section, we looked more specifically into the "other verb" and "other response" categories to gain a complete picture of the responses provided by children with SLI. Figures 4 and 5 show the response type distributions within each category. Figure 4 shows that even when they use another verb, controls tend to use the passé composé, unlike children with SLI, who prefer the present tense. In addition, the production of an auxiliary plus a verb (e.g., il a construire une maison 'he has to-build a house') is found in approximately $15 \%$ of SLI responses in this category, whereas the Control group produces this response type only once. Note that due to the low numbers of these response subtypes for each group, no statistical analyses were performed on them.

\section{INSERT FIGURE 4 ABOUT HERE \\ INSERT FIGURE 5 ABOUT HERE}

Figure 5 shows that only children with SLI produce unintelligible responses, phonological errors, and phrases without a verb. For the Control group, almost $20 \%$ of responses in this category are the imperfect tense production, a past tense form used in stories. and which can be overused by children in story-telling and acting (it bears an irrealis mood), whereas its occurrence is negligible in the SLI group (only once).

In order to assess whether a shorter version of the verb production task-developed to identify children with possible writing disabilities in another task (Phophlo, Rvachew et al., 2017. resubmitted) - was sufficient to identify children with SLI, an analysis with only the ten verbs 


\section{Insensitivity to verb conjugation patterns in French SLI}

used in Phophlo (rire 'laugh', sentir 'smell', remplir 'fill', conduire 'drive', perdre 'lose', boire 'drink', mordre 'bite', battre 'beat', défaire 'undo', and ouvrir 'open') was used for group comparisons. These ten verbs comprised four with -i past participle forms, four with $-\mathrm{u}$ past participles, and two Other past participles. Due to the smaller number of items, only the betweengroup factor participant group was included in the analysis.

We ran $t$-tests on the task global scores (out of 10) to directly compare the two participant groups. Levine's test of variance equality demonstrated differences in variance for the scores. Hence, the Greehouse-Geisser procedure was used for comparisons. We observed a significant difference in favour of the Control group, $t(23.2)=3.94, p=.001$ (Control: $M=5.42, S D=4.25$; SLI: $M=$ 1.37, $S D=1.61)$. We found the same results when isolating the past participle forms. Again, Greenhouse-Geisser corrections were made due to violation of sphericity. The $t$-test revealed a significant difference between the two participant groups in favour of the Control group, $t(27.0)=$ $3.42, p=.002$ (Control: $M=6.05, S D=3.81$; SLI: $M=2.68, S D=1.97)$.

\section{Discussion}

Our results are consistent with previous studies on verb elicitation in other languages, in that children with typical language development distinguish verb conjugation classes and inflection types. We add to this cross-linguistic data by showing that further distinctions in verb production abilities can be linked to the type of verb used within regular and irregular verb classes in French (as seen in Marquis et al., 2012). French-speaking children with SLI do not seem to make these distinctions in our age groups (5;6 to 7;4 years), despite low error rates in spontaneous speech data even at younger ages (e.g., Elin Thordardottir \& Namazi, 2007), indicating a) lack of 


\section{Insensitivity to verb conjugation patterns in French SLI}

sensitivity to verb morphological patterns that are salient in French and b) delayed or deficient mastery of these paradigms extending into the early school years. The particularities of the French verbal system also allow us to disentangle effects that are confounded in English studies, namely frequency and default status for regular verbs. In French, -i verbs are sub-regular but not frequent types. Type frequency thus cannot explain their mastery by French children. The same can be said for the predictable but nonproductive - $\mathrm{u}$ pattern in third conjugation forms. However, children with SLI are insensitive to these patterns. Interestingly, these data parallel those found in Danish and Norwegian elicitation tasks (Lum \& Bleses, 2012; Simonsen \& Bjerkan, 1998; Vang Christensen \& Hansson, 2012), where children with SLI showed protracted mastery of the regular (weak) verbs that had a less frequent pattern, in addition to lower ability to produce highfrequency regular patterns compared to controls.

We also observed differences in nontarget response types produced by the two participant groups: control children typically produced the passé composé form of another verb when not producing the target verb, whereas children with SLI tended to use another verb tense (especially the present) in contexts that required the past tense. However, no significant differences were found between the two participant groups in terms of the number of overregularizations, contrary to what is often found in English, for example.

A potential limitation of this study is the small sample size. Data from larger samples are required to confirm our sensitivity and specificity estimates for the Jeu de verbes for use as a screen for oral language impairment in children entering the French school system. Interestingly, the cut-off for -é verbs is the same independently of group size, suggesting that this might be the most appropriate measure for identifying children with potential oral language difficulties. No -é verbs 


\section{Insensitivity to verb conjugation patterns in French SLI}

are included in the shorter Phophlo task. Thus, even though this shorter version appears to distinguish between our groups, it might not clearly identify children with subtle forms of oral language impairment.

We feel that the mixed language background of our groups is a strength, given the truly multilingual and multicultural contexts in Montreal schools. More than $30 \%$ of the Montreal population is made up of recent immigrants - a number that is growing-, and more than $34 \%$ of this group has a first language other than French or English (Corbeil \& Blaser, 2007). The Montreal School Commission (Commission scolaire de Montréal, CSDM, 2010) states that in 2007-2008, 24\% of the students were born outside of Quebec, and close to 50\% did not speak French as a mother tongue. In addition, more than $37 \%$ spoke a language other than French at home. ${ }^{6}$ However, to validate the screening tool, a larger sample of children would provide greater confidence in the sensitivity and specificity of results. We are currently developing partnerships with schools to enable large-scale data acquisition over multiple institutions with varied sociolinguistic and socio-economic backgrounds.

The diversity of profiles observed indicates that, despite the task's fair sensitivity and moderate specificity, the efficacy of this task as a clinical marker of SLI in the early school years remains uncertain. We believe that this task has the potential for use as primarily a screening tool for further assessment and referral: the shorter version of the Phophlo task for teachers might be sufficient to quickly identify children in a classroom who may be at risk for presenting a

${ }^{6}$ Three other school commissions on the island of Montreal: the Commission scolaire Marguerite-Bourgeoys (CSMB), the Commission scolaire Pointe-de-l'ille (CSPI), and the Commission scolaire Marie-Victorin (CSMV), found similar results. The CSMB notes that 41\% of its students speak a language other than French at home (2013). The CSPI (2013) reports that $31.4 \%$ of students are from immigrant families, without specifying which language is spoken at home. The CSMV (2013) states that $38.2 \%$ of its students are immigrants, and that $25.9 \%$ of elementary school students are allophones (speaking languages other than French). 


\section{Insensitivity to verb conjugation patterns in French SLI}

language disorder. However, as both versions were tested in different conditions and different groups of children, it would be useful to compare them directly in the same children in similar settings in order to assess whether the short or long version is more sensitive to oral language learning disabilities. That said, both versions have short administration times (less than 10 minutes), are visually appealing to children, and have been developed for classroom implementation by nonspecialists.

We believe that by detecting children at risk for presenting language delay or impairment as soon as they enter the school system, this tool will help previously unidentified at-risk language learners be referred to rehabilitation services in speech-language pathology and attenuate subsequent learning difficulties throughout their schooling. This tool is specifically adapted for use by teachers, educators, and SLPs who are concerned about a child's linguistic development. 


\section{Insensitivity to verb conjugation patterns in French SLI}

\section{Acknowledgments}

This study was funded by post-doctoral funding from the FQRSC (Marquis, 2012-2014), SSHRC Institutional funding from the University of Montreal (Royle, 2014-2015), and a summer bursary scholarship from the Faculty of Medicine of the University of Montreal (COPSE) (St-Denis, 2015). We would like to thank the children and their parents, the schools, the teachers, and the speech and language therapists who agreed to participate in the study. We thank two anonymous editors for their thoughtful comments. Special thanks go to Marielle Jullien for her help with testing, Tracy Kawass for data coding, and Margaret McKyes for revision. 
Insensitivity to verb conjugation patterns in French SLI

Appendix A: Characteristics of the children with SLI who participated in this study

\begin{tabular}{|c|c|c|c|c|c|}
\hline Code & $\begin{array}{l}\text { Expressive } \\
\text { impairment }\end{array}$ & $\begin{array}{c}\text { Receptive } \\
\text { impairment }\end{array}$ & Dyspraxia & Medical & Other \\
\hline V01 & Mild-moderate & No & Yes & Twin V03 & $\begin{array}{c}\text { Mild lexical access } \\
\text { impairment }\end{array}$ \\
\hline V03 & Mild-moderate & No & Yes & Twin V01 & \\
\hline V04 & Mild & No & No & $\begin{array}{c}\text { Otitis with } \\
\text { temporary } \\
\text { auditory loss at a } \\
\text { young age }\end{array}$ & $\begin{array}{l}\text { Mild lexical access } \\
\text { impairment, mild } \\
\text { addental lisp }\end{array}$ \\
\hline V06 & Severe & $\begin{array}{l}\text { Moderate- } \\
\text { severe }\end{array}$ & Yes & Twin V08 & Motor delay \\
\hline V07 & Severe & Severe & Yes & - & - \\
\hline V08 & Severe & $\begin{array}{l}\text { Moderate- } \\
\text { severe }\end{array}$ & Yes & Twin V06 & - \\
\hline V09 & Very severe & Very severe & Yes & $\begin{array}{l}\text { Propionic } \\
\text { acidemia }\end{array}$ & - \\
\hline $\mathrm{V} 10$ & Severe & $\begin{array}{l}\text { Moderate- } \\
\text { severe }\end{array}$ & Yes & Brachial plexus & - \\
\hline V11 & Severe & Severe & Yes & Dysarthria & ADHD \\
\hline V13 & Moderate & Moderate & No & - & Stuttering \\
\hline $\mathbf{V} 17$ & Severe & Severe & No & - & - \\
\hline V18 & Severe & Severe & Yes & Tourette & - \\
\hline
\end{tabular}


Insensitivity to verb conjugation patterns in French SLI

\begin{tabular}{|c|c|c|c|c|c|}
\hline & & & & hypothesis & \\
\hline V21 & Moderate & Moderate & Yes & - & ADHD \\
\hline V22 & Severe & Severe & Yes & - & - \\
\hline \multirow[t]{4}{*}{ V25 } & Severe & Severe & Yes & Adopted at 6 & AFS/drugs, \\
\hline & & & & months & placenta previa, \\
\hline & & & & ADHD & hypotension, \\
\hline & & & & hypothesis & diabetes \\
\hline V29 & Severe & Severe & No & - & - \\
\hline \multirow[t]{2}{*}{ V31 } & Severe & Severe & Yes & Fine motor skill & Sensory \\
\hline & & & & delay & sensitivities \\
\hline V35 & Severe & Moderate & No & - & - \\
\hline \multirow[t]{4}{*}{$\mathbf{V 3 7}$} & Severe & Severe & No & Trilingual & Evaluated in \\
\hline & & & & (English at home, & Bengali and \\
\hline & & & & parents also speak & English \\
\hline & & & & Bengali) & \\
\hline
\end{tabular}




\section{Insensitivity to verb conjugation patterns in French SLI}

Appendix B: Properties of target verb types (standard deviation)

\begin{tabular}{|c|c|c|c|c|c|c|}
\hline & & & Number & Number & & \\
\hline Verb & Form & Lemma & of & of & Orthographic & Phonological \\
\hline group & frequency $^{\mathrm{a}}$ & frequency $^{\mathrm{a}}$ & phonemes $^{\mathrm{a}}$ & syllables ${ }^{\mathrm{b}}$ & neighbors $^{\mathrm{a}}$ & neighbors $^{\mathrm{a}}$ \\
\hline \multirow{2}{*}{ /e/ } & 110.4 & 535.6 & 4.17 & 2.00 & 4.83 & 17.67 \\
\hline & (141.4) & $(572.7)$ & $(0.41)$ & $(0)$ & $(1.72)$ & $(8.33)$ \\
\hline \multirow{2}{*}{ /i/ } & 74.5 & 256.0 & 3.86 & 1.71 & 5.43 & 8.86 \\
\hline & (104.9) & $(218.0)$ & (1.07) & $(0.49)$ & $(4.96)$ & $(9.30)$ \\
\hline \multirow{2}{*}{$/ y /$} & 98.0 & 394.0 & 4.17 & 2.00 & 5.33 & 10.33 \\
\hline & (109.1) & (248.9) & (1.17) & $(0.63)$ & $(5.28)$ & $(7.23)$ \\
\hline \multirow{2}{*}{ IR } & 61.7 & 231.5 & 3.71 & 1.71 & 4.17 & 13.50 \\
\hline & $(114.7)$ & $(331.0)$ & (1.11) & $(0.49)$ & $(4.67)$ & $(9.59)$ \\
\hline \multicolumn{7}{|c|}{${ }^{\mathrm{a}}$ From LEXIQUE (New et al., 2001) } \\
\hline \multicolumn{7}{|c|}{${ }^{\mathrm{b}}$ Syllabic structure of Québécois French } \\
\hline \multicolumn{7}{|c|}{ Univariate analyses by verb type, all $F(3,23), p>.1$} \\
\hline
\end{tabular}




\section{Insensitivity to verb conjugation patterns in French SLI}

Appendix C: Written lemma and form frequencies in child literature (standard deviation)

\begin{tabular}{|c|c|c|c|c|c|c|}
\hline Verb & Lemma & Lemma & Lemma & Form & Form & Form \\
\hline group & $\mathrm{CP}^{\mathrm{c}}$ & $\mathrm{CE} 1^{\mathrm{c}}$ & $\mathrm{CP}-\mathrm{CM} 2^{\mathrm{c}}$ & $\mathrm{CP}^{\mathrm{c}}$ & $\mathrm{CE} 1^{\mathrm{c}}$ & $\mathrm{CP}-\mathrm{CM} 2^{\mathrm{c}}$ \\
\hline \multirow{2}{*}{ /e/ } & 678.83 & 780.82 & 652.04 & 84.95 & 70.64 & 70.44 \\
\hline & $(485.00)$ & (773.74) & $(673.42)$ & $(76.84)$ & (74.27) & $(75.79)$ \\
\hline \multirow{2}{*}{ /i/ } & 290.63 & 446.92 & 407.56 & 57.72 & 71.54 & 63.35 \\
\hline & (208.00) & $(567.95)$ & (478.28) & $(57.48)$ & (111.12) & $(85.47)$ \\
\hline \multirow{2}{*}{$/ \mathrm{y} /$} & 333.94 & 390.16 & 358.06 & 69.82 & 40.33 & 52.70 \\
\hline & $(232.32)$ & (394.22) & $(254.40)$ & (108.88) & $(52.52)$ & $(60.72)$ \\
\hline \multirow{2}{*}{ IR } & 157.03 & 128.97 & 156.68 & 21.22 & 17.18 & 23.22 \\
\hline & $(230.96)$ & (163.33) & (164.71) & $(25.73)$ & $(9.20)$ & $(14.12)$ \\
\hline \multicolumn{7}{|c|}{${ }^{\mathrm{c}}$ From MANULEX (Lété et al., 2004) } \\
\hline \multicolumn{7}{|c|}{$\mathrm{CP}=$ cours préparatoire 'preschool' (6 years) } \\
\hline \multicolumn{7}{|c|}{ CE1 = cours élémentaire 1 'elementary course'(7 years) } \\
\hline \multicolumn{7}{|c|}{$\mathrm{CM} 2=$ cours moyen 2 'medium course' $(11$ years $)$} \\
\hline Univaria & lyses by & type, all & 1 & & & \\
\hline
\end{tabular}




\section{Insensitivity to verb conjugation patterns in French SLI}

Appendix D: Example of an image used during the procedure (for cacher 'to hide').

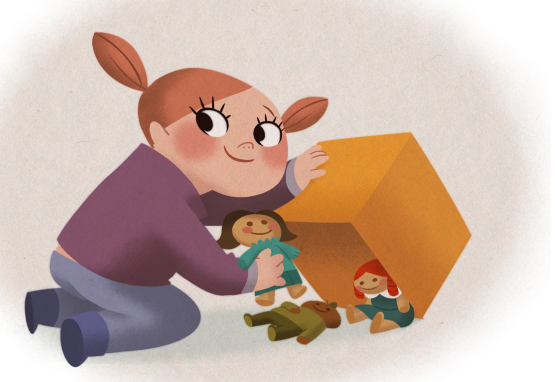

C All rights reserved by Édith Lebel. 


\section{Insensitivity to verb conjugation patterns in French SLI}

Statement of Interest. The authors have no conflicts of interest to declare, and the funding agencies had no say in this research. 


\section{Insensitivity to verb conjugation patterns in French SLI}

\section{References}

Abdalla, F., \& Crago, M. (2008). Verb Morphology Deficits in Arabic-Speaking Children with Specific Language Impairment. Applied Psycholinguistics, 29(2), 315-340.

Bassano, D., Maillochon, I., Klampfer, S., \& Dressler, W. (2001). L’acquisition de la morphologie verbale en français et en allemand autrichien: II. L'épreuve des faits. Enfance(53), 117-148.

Bedore, L. M., \& Leonard, L. B. (2001). Grammatical Morphology Deficits in Spanish-Speaking Children with Specific Language Impairment. Journal of Speech, Language, and hearing research, 44(4), 905-924.

Bedore, L. M., \& Leonard, L. B. (2005). Verb inflections and noun phrase morphology in the spontaneous speech of Spanish-speaking children with specific language impairment. Applied Psycholinguistics, 26(2), 195-225.

Bishop, D. V. M. (2014). Problems with tense marking in children with specific language impairment: not how but when. Philisophical Transactions of the Royal Society B, 369, 20120401. doi:10.1098/rstb.2012.0401

Bortolini, U., Caselli, M. C., Deevy, P., \& Leonard, L. B. (2002). Specific language impairment in Italian: the first steps in the search for a clinical marker. International Journal of Language and Communication Disorders, 37(2), 77-93.

Bortolini, U., Leonard, L. B., \& Caselli, M. C. (1998). Specific language impairment in Italian and English: Evaluating alternative accounts of grammatical deficits. Language and Cognitive Processes, 13(1), 1-20.

Clahsen, H. (1989). The grammatical characterization of developmental dysphasia. Linguistics, 27, 897-920. 


\section{Insensitivity to verb conjugation patterns in French SLI}

Clahsen, H. (1996). The representation of participles in the German mental lexicon: Evidence for the dual-mechanism model. In G. Booij \& J. van Marle (Eds.), Yearbook of Morphology (pp. 73-95). Dordrecht: Kluwer Academic Publishers.

Clahsen, H., \& Hansen, D. (1993). The missing agreement account of specific language impairment: evidence from therapy experiments. Retrieved from

Corbeil, J.-P., \& Blaser, C. (2007). Le portrait linguistique en évolution. Retrieved from http:/www12.statcan.ca/census-recensement/2006/as-sa/97-555/pdf/97-555XIF2006001.pdf

CSDM (2010). Rapport annuel d'évaluation 2008-2009 : Le bilan du plan stratégique. Retrieved from http://www.csdm.qc.ca/CSDM/MissionEnjeux/RapportsEvaluation.aspx

CSMB (2013). Rapport annuel 2012-2013. Retrieved from http://www.csmb.qc.ca/fr$\underline{\mathrm{CA} / \mathrm{csmb} / \text { rapport-annuel-12-13.aspx }}$

CSMV (2013). Rapport annuel 2011-2012. Retrieved from http://www.csmv.qc.ca/blog/2013/01/diffusion-du-rapport-annuel-2011-2012/

CSPI (2013). Rapport annuel 2012-2013. Retrieved from http://www.cspi.qc.ca/index.php?option=com_docman\&Itemid=39

Dromi, E., Leonard, L. B., \& Shteiman, M. (1993). The grammatical morphology of Hebrewspeaking children with specific language impairment: Some competing hypotheses. Journal of Speech and Hearing Research, 36, 760-771.

Elin Thordardottir (2008). Language-specific effects of task demands on the manifestation of specific language impairment: a comparison of English and Icelandic. Journal of Speech, Language, and hearing research, 51, 922-937. doi:10.1044/1092-4388(2008/068) 


\section{Insensitivity to verb conjugation patterns in French SLI}

Elin Thordardottir \& Namazi, M. (2007). Specific Language Impairment in French-Speaking Children: Beyond Grammatical Morphology. Journal of Speech, Language, and hearing research, 50(3), 698-715.

Franck, J., Cronel-Ohayon, S., Chillier, L., Frauenfelder, U. H., Hamann, C., Rizzi, L., \& Zesiger, P. (2004). Normal and pathological development of subject-verb agreement in speech production: A study on French children. Journal of Neurolinguistics, 17(2-3), 147180.

Gopnik, M., Dalalakis, J., Fukuda, S. E., Fukuda, S., \& Kehayia, E. (1997). Genetic language impairment: Unruly grammars. In W. G. Runciman \& J. Maynard (Eds.), Evolution of social behavior patterns in primates and man. Proceedings of the British Academy, 88 (pp. 223-249). Oxford, UK: Oxford University Press.

Grégoire, A. (1937). L'apprentissage du langage. Paris: Droz.

Groupe coopératif en orthophonie - Région Laval, L., Lanaudière. (1995). Adaptation française du Expressive One-Word Picture Vocabulary Test-R [French adaptation of Gardner's Expressive One-Word Picture Vocabulary Test]. Laval, Québec, Canada.

Hansson, K. (1997). Patterns of verb usage in Swedish children with SLI: An application of recent theories. First Language, 17(50, pt. 2), 195-217.

Hansson, K., Nettelbladt, U., \& Leonard, L. B. (2000). Specific language impairment in Swedish: the status of verb morphology and word order. Journal of Speech, Language and Hearing Research, 43(4), 848-864.

Hiriarteborde, A. (1973). Sur la généralisation de quelques marques grammaticales dans le langage d'enfants de 3 ans 1/2. Études de Linguistique Appliquée, 9, 101-124. 


\section{Insensitivity to verb conjugation patterns in French SLI}

Jakubowicz, C. (2003). Computational complexity and the acquisition of functional categories by French-speaking children with SLI. Linguistics, 41(2), 171-211.

Junyent, A., Levorato, M., \& Denes, G. (2010). Verbal inflection, articles and object clitics in Italian specific language impairment. Clinical Linguistics \& Phonetics, 24(11), 941-954. doi:10.3109/02699206.2010.511409

Kunnari, S., Savinainen-Makkonen, T., Leonard, L. B., Makinen, L., Tolonen, A.-K., Luotonen, M., \& Leinonen, E. K. (2011). Children with specific language impairment in Finnish: the use of tense and agreement inflections. Journal of Child Language, 38(5), 999-1027. doi: $10.1017 / \mathrm{S} 0305000910000528$

Leonard, L. B. (2014). Children with specific language impairment (2nd Ed.). Cambridge, MA: MIT Press.

Leonard, L. B., Bortolini, U., Caselli, M. C., McGregor, K. K., \& Sabbadini, L. (1992). Morphological deficits in children with specific language impairment: the status of features in the underlying grammar. Language Acquisition, 2(2), 151-179.

Leonard, L. B., Lukács, Á., \& Kas, B. (2012). Tense and aspect in childhood language impairment: Contributions from Hungarian. Applied Psycholinguistics, 33, 305-328. doi:10.1017/S0142716411000361

Leroy, S., Parisse, C., \& Maillart, C. (2014). Le manque de généralisation chez les enfants dysphasiques : une étude longitudinale. Approche neuropsychologique des apprentissages chez l'enfant (A.N.A.E.), 131, 357-365.

Lété, B., Sprenger-Charolles, L., \& Colé, P. (2004). MANULEX : A grade-level lexical database from French elementary-school readers. Behavior Research Methods, Instruments, \& Computers, 36, 156-166. 


\section{Insensitivity to verb conjugation patterns in French SLI}

Lukács, Á., Leonard, L. B., Kas, B., \& Pléh, C. (2009). The Use of Tense and Agreement by Hungarian-Speaking Children with Language Impairment. Journal of Speech, Language and Hearing Research, 52(1), 98-117. doi:10.1044/1092-4388(2008/07-0183)

Lum, J. A. G., \& Bleses, D. (2012). Declarative and procedural memory in Danish speaking children with specific language impairment. Journal of Communication Disorders, 45, 46-58.

Marquis, A. (2012-2014). Le rôle des groupes de verbes dans le développement du langage chez l’enfant francophone L1 et bilingue séquentiel L2 au Québec. Montreal, Québec: FQRSC.

Marquis, A. \& Royle, P. (in preparation). Verbs and patterns in native and second language learners of French.

Marquis, A., \& Royle, P. (2015). Are Second Language Learners Just as Good at Verb Morphology as First Language Learners? Paper presented at the BUCLD 39 Boston, MA. http://www.bu.edu/bucld/files/2015/06/Marquis.pdf

Marquis, A., Royle, P., Gonnerman, L. M., \& Rvachew, S. (2012). La conjugaison du verbe en début de scolarisation. TIPA. Travaux interdisciplinaires sur la parole et le langage 28, 13.

Marshall, C. R., \& van der Lely, H. K. J. (2007). The impact of phonological complexity on past tense inflection in children with Grammatical-SLI. Advances in Speech-Language Pathology, 9, 191-203.

MELS. (2013). Programme de formation de l'école québécoise. Retrieved from http://www1.mels.gouv.qc.ca/sections/programmeFormation/primaire/index.asp?page=prf orm2001h 


\section{Insensitivity to verb conjugation patterns in French SLI}

New, B., Pallier, C., Ferrand, L., \& Matos, R. (2001). Une base de données lexicales du français contemporain sur internet : LEXIQUE. L'Année Psychologique, 101, 447-462.

Paradis, J., \& Crago, M. (2001). The Morphosyntax of Specific Language Impairment in French: An Extended Optional Default Account. Language Acquisition, 9(4), 269-300.

Pinker, S., \& Prince, A. (1992). Regular and irregular morphology and the psychological status of rules of grammar. In L. A. Sutton, C. Johnson, \& R. Shields (Eds.), Proceedings of the 17th annual meeting of the Berkeley linguistics society: General session and parasession on the grammar of event structure (pp. 230-251). Berkeley, CA: Berkeley Linguistics Society.

Pizzioli, F., \& Schelstraete, M.-A. (2008). The argument-structure complexity effect in children with specific language impairment: Evidence from the use of grammatical morphemes in French. Journal of Speech, Language \& Hearing Research, 51, 706-721.

Plante, E., \& Vance, R. (1994). Selection of preschool language tests: a data-based approach. Language, Speech, and Hearing Services in Schools, 25, 12-24.

Rice, M. L., \& Wexler, K. (1996). Toward tense as a clinical marker of specific language impairment in English-speaking children. Journal of Speech, Language, and hearing research, 39, 1236-1257.

Rice, M. L., Wexler, K., \& Cleave, P. (1995). Specific Language Impairment as a Period of Extended Optional Infinitive. Journal of Speech and Hearing Research, 38, 850-863.

Rice, M. L., Wexler, K., \& Hershberger, S. (1998). Tense over time: The longitudinal course of tense acquisition in children with specific language impairment. Journal of Speech, Language, and hearing research, 41, 1412-1431. 


\section{Insensitivity to verb conjugation patterns in French SLI}

Rose, Y., \& Royle, P. (1999). Uninflected structure in familial language impairment: evidence from French. Folia Phoniatrica et Logopaedica, 51(1-2), 70-90. doi:21482

Royle, P. (2007). Variable effects of morphology and frequency on inflection patterns of French preschoolers. The Mental Lexicon Journal, 2(1), 103-125.

Royle, P., Beritognolo, G., \& Bergeron, E. (2012). Regularity, sub-regularity and irregularity in French acquisition. In J. van der Auwera, T. Stolz, A. Urdze, \& H. Otsuka (Eds.), Irregularity in Morphology (and Beyond) (pp. 227-250). Berlin: Akademie Verlag.

Royle, P., \& Thordardottir, E. T. (2008). Elicitation of the passe compose in French preschoolers with and without specific language impairment. Applied Psycholinguistics, 29(3), 1-22. doi: $10.1017 / \mathrm{S} 0142716408080168$

Rvachew, S., Marquis, A., Paul, M., Brosseau-Lapré, F., Gonnerman, L., \& Royle, P. (2013). Speech Articulation Performance of Francophone Children in the Early School Years: Norming of the Test Dépistage Francophone de Phonologie. Clinical Linguistics and Phonetics, 27(12), 950-968. doi:10.3109/02699206.2013.830149

Rvachew, S., Royle, P., Gonnerman, L., Stanké, B., Marquis, A., \& Herbay, A. (resubmitted). Development of a Tool to Screen Risk of Literacy Delays in French-Speaking Children: PHOPHLO. Canadian Journal of Speech-Language Pathology and Audiology.

Rvachew, S., Royle, P., Gonnerman, L. M., Stanké, B., Marquis, A., \& Herbay, A. (2017). Phophlo (Version 1.0). Retrieved from https://itunes.apple.com/us/app/phophlo/id1196330610?mt=8

Simonsen, H. G., \& Bjerkan, K. M. (1998). Testing past tense inflection in Norwegian: a diagnostic tool for identifying SLI children? International Journal of Applied Linguistics, 8(2), 251-270. doi:10.1111/j.1473-4192.1998.tb00132.x 


\section{Insensitivity to verb conjugation patterns in French SLI}

Spoelman, M., \& Bol, G. (2012). The use of subject-verb agreement and argument structure in monolingual and bilingual children with specific language impairment. Clinical Linguistics \& Phonetics, 26, 357-379.

Stavrakaki, S. (2005). Greek neurolinguistics: The State of the Art. Journal of Greek Linguistics, 6(1), 187-234. doi:10.1075/jgl.6.10sta

Stavrakaki, S., Chrysomallis, M.-A., \& Petraki, E. (2011). Subject-verb agreement, object clitics and wh-questions in bilingual French-Greek SLI: the case-study of a French-Greekspeaking child with SLI. Clinical Linguistics and Phonetics, 25(5), 339-367. doi:10.3109/02699206.2010.538954

Ullman, M. T., Corkin, S., Coppola, M., Hickok, G., Growdon, J. H., Koroshetz, W. J., \& Pinker, S. (1997). A Neural Dissociation within Language: Evidence that the Mental Dictionary Is Part of Declarative Memory, and that Grammatical Rules Are Processed by the Procedural System. Journal of Cognitive Neuroscience, 9(2), 266-276.

Ullman, M. T., \& Gopnik, M. (1994). Past tense production: regular, irregular and nonsense verbs. McGill Working Papers in Linguistics, 10, 81-118.

van der Lely, H. K. J., \& Ullman, M. T. (2001). Past tense morphology in specifically language impaired and normally developing children. Language and Cognitive Processes, 16(2), 177-217.

Vang Christensen, R., \& Hansson, K. (2012). The use and productivity of past tense morphology in specific language impairment: An examination of Danish. Journal of Speech, Language and Hearing Research, 55(6), 1671-1689. doi:10.1044/1092-4388(2012/10-0350) 